\title{
O Plano Nacional de Educação 2014-2024 e os desafios para a Educação Especial na perspectiva de uma Cultura Inclusiva
}

\author{
Janaina de Oliveira Macena a \\ Laura Regina Paniagua Justino ${ }^{b}$ \\ Vera Lúcia Messias Fialho Capellini ${ }^{c}$
}

\section{Resumo}

Este estudo situa-se diante dos caminhos que vêm sendo trilhados no Brasil na implementação de políticas públicas na área da educação, voltadas para uma Cultura Inclusiva. Apresenta-se um breve levantamento histórico sobre o trajeto das lutas sociais, na garantia de direitos, até o presente momento em que políticas públicas estão atentas a esse tema. $\mathrm{O}$ recorte analítico se dá no levantamento de indicadores para a meta 4 do Plano Nacional de Educação, a qual estabelece o planejamento de ações voltadas à Educação Inclusiva para a próxima década. Nesse sentido, são apresentados dados sobre: a evolução das matrículas de alunos com deficiência, formação de docentes para atender a esse público específico e relativos à implantação e ao uso das salas de recursos multifuncionais. As referências utilizadas são provenientes da base de dados do INEP (Instituto Nacional de Estudos e Pesquisas Educacionais Anísio Teixeira). Os dados analisados consideram o cruzamento dos números do Censo Escolar e do Censo Demográfico do IBGE (Instituto Brasileiro de Geografia e Estatística). Palavras-chave: Plano Nacional de Educação 2014-2024. Educação Inclusiva. Cultura Inclusiva.

\footnotetext{
a Universidade Estadual Paulista Júlio de Mesquita Filho. Bauru, São Paulo, Brasil.

b Universidade Estadual Paulista Júlio de Mesquita Filho. Bauru, São Paulo, Brasil.

c Universidade Estadual Paulista Júlio de Mesquita Filho. Bauru, São Paulo, Brasil. 


\section{Introdução}

A sociedade brasileira carrega em suas raízes a história de uma institucionalização da educação iniciada em um processo de colonização do país, que, por si só, garante em sua base uma educação espelhada em costumes europeus e americanos. Assim, conforme nos esclarece Lopes (2014):

Desde a consolidação do modo capitalista de produção (meados do século XIX), nos principais países da Europa Ocidental e da América do Norte, com a ascensão da burguesia como classe dominante, esta passou a utilizar a educação como um dos elementos para propagar sua ideologia e contribuir na manutenção da ordem que havia estabelecido (LOPES, 2014, p. 739).

No Brasil o caminho foi o mesmo, expandindo-se também para a educação especial, inexistente por um longo período marcado pelo abandono da criança com deficiência, passando pela institucionalização influenciada pela medicina, chegando, posteriormente, à integração, o que significou atendimento especializado com a garantia de direitos, que culmina, por fim, em um paradigma em construção desde a década de 1990 - a inclusão.

Lopes (2014) pontua que, por volta de 1950, ocorreu a expansão da educação especial no Brasil, resultando nas décadas de 1960 e 1970, em praticamente um subsistema de educação, sendo este concomitante à concretização da rede privada.

Portanto, culturalmente, a população passa por diferentes mudanças na educação proporcionadas pelos acontecimentos históricos e sociais, evidenciando ainda mais a diversidade, e intensificando o paradigma da inclusão, a partir da democratização do ensino.

Se por um lado, a democratização do ensino e a universalização da escola foram ideológica e amplamente disseminadas como instrumento de ascensão social às classes populares e às minorias excluídas, por outro lado houve indicação para a educação especial, além do alunado que apresentava deficiências, também daqueles que fracassavam por não se adequarem à escola (LOPES, 2014, p. 740).

Ao quantificar toda essa relação histórico-cultural entre a diversidade humana e o contexto escolar, a educação especial passou a abranger uma parcela da população com dificuldades de aprendizagem e/ou dificuldades de adequação. 
Com vistas à democratização do ensino, que busca a promoção de uma escola que atenda os indivíduos de diferentes segmentos populacionais, a Educação Especial assume um novo papel, caracterizando-se como parte integrante da escola comum, disponibilizando suporte necessário para dar oportunidade de aprendizado a todos os alunos (MARTINS; LEITE, 2014, p. 196).

Esse processo aumentou o índice de fracasso escolar que foi diretamente relacionado ao movimento de "escola para todos", aumentando concomitantemente a demanda e a consolidação de diversas instituições filantrópicas, dispostas ao atendimento de casos mais graves, mas que, dificilmente, negavam atendimento a quem os procurassem.

Desde então, inúmeras ações aconteceram em torno do atendimento ao aluno com dificuldades de aprendizagem e em busca do reconhecimento do papel do Estado nesse contexto. A Constituição Federal de 1988, no Art. 206, passa a garantir o ensino para todos em igualdade de condições, complementado pelo Art. 207, que diz ser dever da família, da sociedade e do Estado assegurar à criança e ao adolescente, entre outras coisas, o direito à educação, à cultura, ao respeito, além de colocá-los a salvo de discriminação e violência. (BRASIL, 1988)

A partir dos direitos assegurados na Constituição, o Estatuto da Criança e do Adolescente (ECA) reitera esses direitos, e o Brasil participa do movimento internacional pela Educação Inclusiva, integrando os diversos acordos e convenções do assunto pelo mundo. Por sua vez, as Leis Diretrizes e Bases para a Educação Nacional (BRASIL, 1996) confirma o direito de os alunos com deficiência frequentarem as classes comuns, de preferência na rede regular de ensino.

Nessa perspectiva, em 1998 o Ministério da Educação (MEC) lança um documento contendo as adaptações curriculares que devem ser feitas nos Parâmetros Curriculares Nacionais (PCN) (BRASIL, 1998), culminando em 2001 na publicação das Diretrizes Nacionais para a Educação Especial na Educação Básica.

No artigo 59 da LDBEN n ${ }^{\circ}$ 9.394/96 (BRASL, 1996), na redação dada pela Lei $\mathrm{n}^{\mathrm{o}} 12.796$ de 2013, é apresentado o seguinte texto:

Os sistemas de ensino assegurarão aos educandos com deficiência, transtornos globais do desenvolvimento e altas habilidades ou superdotação: 
I - currículos, métodos, técnicas, recursos educativos e organização específicos, para atender às suas necessidades;

II - terminalidade específica para aqueles que não puderem atingir o nível exigido para a conclusão do ensino fundamental, em virtude de suas deficiências, e aceleração para concluir em menor tempo o programa escolar para os superdotados;

III - professores com especialização adequada em nível médio ou superior, para atendimento especializado, bem como professores do ensino regular capacitados para a integração desses educandos nas classes comuns;

IV - educação especial para o trabalho, visando a sua efetiva integração na vida em sociedade, inclusive condições adequadas para os que não revelarem capacidade de inserção no trabalho competitivo, mediante articulação com os órgãos oficiais afins, bem como para aqueles que apresentam uma habilidade superior nas áreas artística, intelectual ou psicomotora;

V - acesso igualitário aos benefícios dos programas sociais suplementares disponíveis para o respectivo nível do ensino regular.

Apesar de toda a legislação existente, incluindo a Lei Brasileira de Inclusão aprovada em 2015 (BRASIL, 2015), no sentido da garantia de direitos, concordamos com Martins e Leite (2014) ao pontuarem a necessidade de reconhecermos uma dada evolução na formulação de políticas que norteiam a perspectiva inclusiva em educação, porém, o que encontramos na prática é que as necessidades apresentadas pelos alunos, para concretizar um progresso acadêmico, estão para além dos dispostos normativos.

À parte estas considerações apresentadas, essas ações foram importantes para desencadear a inserção do assunto no Plano Nacional de Educação (PNE), Lei $\mathrm{n}^{\mathrm{o}}$ 10.172/2001 (BRASIL, 2001), que estabelece entre seus objetivos e metas o favorecimento do atendimento às necessidades educacionais especiais dos alunos, em salas de aula comuns.

Nesse sentido, o PNE no Brasil almeja considerar toda a diversidade do país, que, tendo larga extensão e recebendo influência de culturas diversas, apresenta peculiaridades no ensino em cada canto da nação. Considerando tais aspectos, 
atentar para determinados fatores contribui para consolidação de uma política pública que respeita e engloba o maior número possível de sujeitos.

Face ao exposto, o ano de 2008 marca importantes conquistas no atendimento ao aluno com deficiência, graças ao Decreto $n^{0}$ 6.571/2008 (BRASIL, 2008a) que dispõe sobre a ampliação de oferta do atendimento educacional especializado nas escolas públicas, e a elaboração da Política Nacional de Educação Especial na Perspectiva da Educação Inclusiva (BRASIL, 2008b).

De acordo com a Política Nacional de Educação Especial na Perspectiva da Educação Inclusiva, criada pelo Ministério da Educação em 2008, os estudantes com deficiência, transtornos globais do desenvolvimento e altas habilidades ou superdotação, segmentos que compõem o público alvo da Educação Especial, têm o direito a frequentar a sala de aula comum e, quando necessário, receber atendimento educacional especializado no período inverso ao da escolarização. Historicamente, essas pessoas foram excluídas do sistema educacional ou encaminhadas para escolas e classes especiais (OBSERVATÓRIO DO PNE, 2013).

No ano seguinte, em 2009, a Resolução n ${ }^{\circ}$ 4/2009 institui as Diretrizes Operacionais para o Atendimento Educacional Especializado, na Educação Básica. Dessa maneira, percebe-se que a partir da implantação das políticas supracitadas, houve um crescimento considerável de matrículas de alunos da educação especial nas classes comuns da rede regular de ensino, no entanto, isso não tem representado a efetividade de uma cultura inclusiva nas escolas do Brasil, como apontam os estudos de Bezerra (2012; 2017) e Barros, Silva e Costa (2015).

\section{Educação Inclusiva e a criação de novas culturas}

A partir do pressuposto da capacidade da Educação Inclusiva produzir uma nova forma de convivência dentro dos ambientes escolares, vislumbramos esta, como uma oportunidade de consolidação de um novo modelo de trocas, que se torna inclusiva por abranger a diversidade dos sujeitos, em fase escolar, por envolver todos os atores da equipe e por ter, entre os seus princípios, a não discriminação.

A Educação Inclusiva, segundo Martins e Leite (2014, p. 198): "tem como pressuposto básico reconhecimento do direito de todos a uma educação justa, igualitária e que atenda às necessidades educacionais especiais de cada indivíduo, que os levem ao desenvolvimento acadêmico e emancipação social.” Os autores 
complementam a necessidade de "considerar os suportes necessários à sua implantação, como, no caso, a rede de apoio, que deve ser pensada como um complemento escolar, não substituindo o processo pedagógico desenvolvido no ensino comum".

Mattos e Mendes (2014), em um estudo amplo sobre a produção acadêmica no assunto, concluem ações necessárias, condizentes com o relato de Martins e Leite (2014), para a concretização de uma cultura inclusiva, quais sejam:

Assegurar avanços efetivos ao processo de implementação da proposta inclusiva significa, além da ampliação do acesso: produção de conhecimentos, realizada pela pesquisa científica em diversas áreas; investimento na qualificação dos educadores para uma atuação mediadora mais competente; ampliação e diversificação das equipes da educação especial dos municípios, e ampliação ou revisão dos modelos de intervenção junto aos diversos atores da comunidade escolar, a fim de responder satisfatoriamente às necessidades formativas, de apoio psicológico, de suporte aos docentes e familiares, além de orientação às práticas pedagógicas dos educadores (MATOS; MENDES, 2014, p. 52).

Assim, as políticas voltadas para uma Educação Inclusiva devem sempre ressaltar, em suas afirmativas, a necessidade de reunião de esforços para acolhimento das diferenças. Acolhimento no sentido de permitir no ambiente de convívio escolar que cada uma das pessoas e dos grupos estejam reconhecidas no processo de ensino-aprendizagem, abrangendo e proporcionando a criação de várias culturas. Segundo Booth e Ainscow (2012, p. 46):

As culturas são modos relativamente permanentes de vida que criam comunidades de pessoas, e são construídos por elas. As culturas são estabelecidas e expressas através da linguagem e dos valores, em histórias, conhecimento, habilidades, crenças, textos, arte, artefatos, regras formais e informais, rituais, sistemas e instituições compartilhados.

Os autores complementam ressaltando que as culturas inclusivas encorajam o reconhecimento de que uma variedade de modos de vida e formas de identidade podem coexistir, que a comunicação entre eles é enriquecedora e exige que se deixe de lado a diferença de poder (BOOTH; AINSCOW, 2012, p. 46) A partir disso, consideramos que as ações propostas no campo da Educação para um 
ambiente inclusivo, aberto à recepção da diversidade, é um passo importante na transformação da sociedade como um todo, visto que se reflete em outras instâncias da convivência humana.

Neste sentido, concordamos com Lopes (2014, p. 738) ao afirmar que: A educação não pode ser compreendida fora da realidade social da qual faz parte e de forma abstrata, já que está inserida num contexto social concreto e, como tal, acaba por evidenciar e reforçar os elementos desse contexto no processo formativo dos indivíduos.

\section{O PNE (e a Meta 4) enquanto diretriz para uma educação inclusiva}

$\mathrm{O} \mathrm{PNE}^{1}$ é fruto de determinações legais presentes na Constituição Federal de 1988 - "A lei estabelecerá o plano nacional de educação, duração plurianual, visando à articulação e ao desenvolvimento do ensino em seus diversos níveis e à integração das ações do Poder Público [...]" (BRASIL, 1988, Art. 214) -, e na Lei de Diretrizes e Bases da Educação Nacional LDBEN n 9.394, de 20 de dezembro de 1996 - A União incumbir-se-á de elaborar o plano nacional de educação, em colaboração com os estados, o DF [Distrito Federal] e os municípios (BRASIL, 1996).

A mais recente versão do PNE, que compreende o decênio 2014-2024, estabelece 20 metas:

Os 20 itens do PNE elencam as "metas estruturantes para a garantia do direito à educação básica com qualidade" (BRASIL, 2014b, p. 9), o que é destacado com tipografia em negrito no Caderno Digital. As seis metas iniciais tratam do acesso ao ensino, e da ampliação e continuidade do atendimento escolar e das oportunidades de escolarização em vários níveis, valorizando os sistemas que incluem todos, isto é, minorias ou desfavorecidos de todo o tipo (econômico, intelectual etc.). A noção de "universalização" é recorrente, compreendida como uma necessidade (ALVARENGA; MAZZOTTI, 2017, p. 189).

No entanto, daremos ênfase especificamente à Meta 4 para avaliação do tema base da discussão do presente estudo. Vale ressaltar que a Meta 4 do PNE consiste em:

O PNE é uma lei ordinária com vigência de dez anos a partir de 26/06/2014, que estabelece diretrizes, metas e estratégias de concretização no campo da Educação. Municípios e unidades da federação devem ter seus planos de Educação aprovados em consonância com essa lei. 


\begin{abstract}
Universalizar, para a população de 4 a 17 anos com deficiência, transtornos globais do desenvolvimento e altas habilidades ou superdotação, o acesso à educação básica e ao atendimento educacional especializado, preferencialmente na rede regular de ensino, com a garantia de sistema educacional inclusivo, de salas de recursos multifuncionais, classes, escolas ou serviços especializados, públicos ou conveniados (BRASIL, 2014, p. 11).
\end{abstract}

Conforme preconiza o texto da referida meta, o foco está no atendimento da pessoa com algum tipo de deficiência, altas habilidades ou superdotação, não menciona as questões relacionadas a outros fatores associados à inclusão escolar, como, por exemplo, às questões referentes às diferenças étnicas. No entanto, esta meta é a que mais se aproxima da formalização do ensino baseado numa Cultura Inclusiva, que visa acima de tudo ao latendimento a todos os cidadãos, independentemente de qualquer característica que os diferencie dos demais.

\title{
4 Metodologia
}

Este artigo tem como base orientadora a Meta 4 do Plano Nacional de Educação, tomando como referência os dados da evolução da Educação Especial no Brasil. Vale destacar que o método utilizado para este estudo foi executado por meio de pesquisa nas bases de dados públicos do Censo Escolar e Censo Demográfico, disponibilizados no Portal do MEC por meio do Instituto Nacional de Estudos e Pesquisas Educacionais Anísio Teixeira (INEP) e com base em estudos anteriores sobre o referido tema.

O Censo Demográfico, que é conduzido pelo Instituto Brasileiro de Geografia e Estatística (IBGE), representa o resultado de uma pesquisa domiciliar que investiga características sociais, econômicas e demográficas da população brasileira, como sexo, idade, educação, trabalho, renda, entre outros temas. Uma de suas limitações é a periodicidade espaçada, com intervalo de 10 anos, o que dificulta comparações mais aproximadas.

O Censo Escolar é uma coleta de dados coordenada pelo INEP, que realiza o levantamento de dados estatísticos educacionais em todo o país, com frequência anual. Todas as instituições educacionais, públicas e privadas, participam do Censo.

Trata-se do principal instrumento de coleta de informações da educação básica, que abrange as suas diferentes etapas e modalidades: ensino regular (educação Infantil e ensinos fundamental e médio), educação especial, educação de jovens e adultos (EJA) e educação 
profissional (cursos técnicos e cursos de formação inicial continuada ou qualificação profissional). O Censo Escolar coleta dados sobre estabelecimentos de ensino, turmas, alunos, profissionais escolares em sala de aula, movimento e rendimento escolar (INEP, 2012).

Os dados coletados por meio do Censo Escolar são utilizados para mapear a situação da educação básica no Brasil, e subsidiam a aplicação de recursos e a implementação de políticas públicas voltadas ao desenvolvimento da educação. Tais fontes de dados, no entanto, dificultam comparações pelo fato de adotarem critérios significativamente diferentes para a caracterização da deficiência.

Além disso, o Censo Demográfico não faz nenhuma referência à população com transtornos globais do desenvolvimento e altas habilidades, ou superdotação. Consequentemente, por enquanto, não é possível construir indicadores precisos para o acompanhamento da Meta 4, tendo em vista que não estão disponíveis ainda fontes de dados fidedignos para esse fim.

Conforme exposto no Portal do PNE, o indicador é calculado considerando todas as matrículas em classes comuns de alunos com deficiência, transtornos globais do desenvolvimento e altas habilidades ou superdotação, em relação ao total de matrículas desses alunos.

Apesar de não entrarem no cálculo as matrículas no atendimento complementar à escolarização, se o mesmo aluno tem duas matrículas de escolarização, ele será contabilizado duas vezes. Como consta no texto da meta universalizar o atendimento preferencialmente na rede regular de ensino, consideramos apenas as matrículas em classes comuns, ou seja, excluímos matrículas em classes especiais ou escolas exclusivas. (OBSERVATÓRIO DO PNE, 2013).

Para este estudo, optou-se por discutir os números dos seguintes indicadores: escolas com salas multifuncionais em uso; escolas com salas multifuncionais sem uso; evolução na porcentagem de matrículas de alunos com deficiência, transtornos globais do desenvolvimento e altas habilidades ou superdotação matriculados em classes comuns; evolução do número de funções docentes no Atendimento Educacional Especializado na rede pública e a evolução da porcentagem de escolas com dependências e vias adequadas a alunos com deficiência ou mobilidade reduzida.

Os indicadores citados são discutidos neste estudo, à luz de teóricos que versam sobre as questões da educação inclusiva. 


\section{Apresentação e discussão dos dados}

No que se refere à quantidade de matrículas de alunos com deficiência, transtornos globais do desenvolvimento e altas habilidades, em classes comuns, é possível observar, por meio do gráfico a seguir (Figura 1), que há uma evolução considerável nesse número.

Os dados estatísticos indicam que, no ano de 2014, havia 698.768 estudantes da educação especial matriculados em classes comuns, desse total 92,7\% estão em classes comuns da rede pública, o que corresponde a 655.375 alunos.

Em 1998 eram aproximadamente 200 mil, sendo apenas 13\% em classes comuns, e esse número aumentava para 285.923(duzentos e oitenta e cinco mil, novecentos e vinte e três) alunos, representando $69,7 \%$. Ou seja, em uma série histórica, há um crescimento das matrículas desse público, apresentando uniformidade desse aumento em todas as regiões do país.

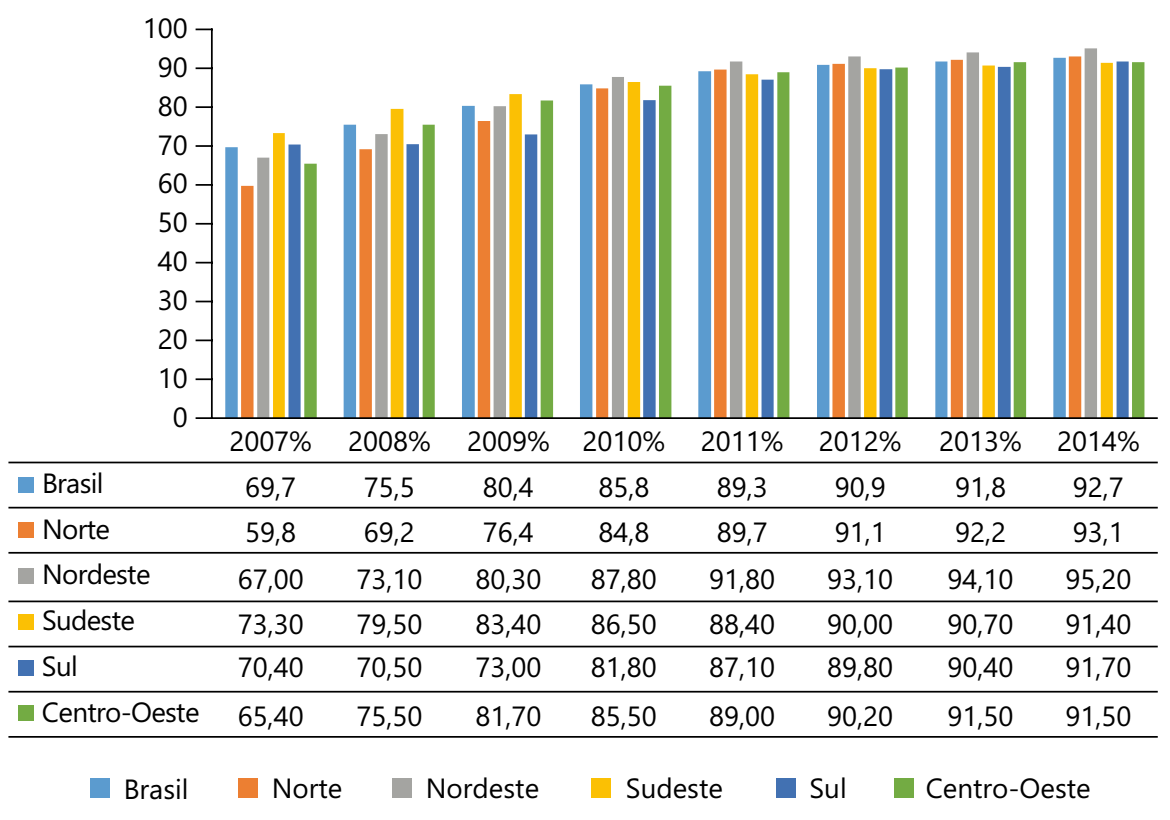

Fonte: INEP (2014) - gráfico elaborado pelas autoras em abril de 2016.

Figura 1. Porcentagem de matrículas de alunos com deficiência, transtornos globais do desenvolvimento e altas habilidades ou superdotação matriculados em classes comuns da rede pública. 


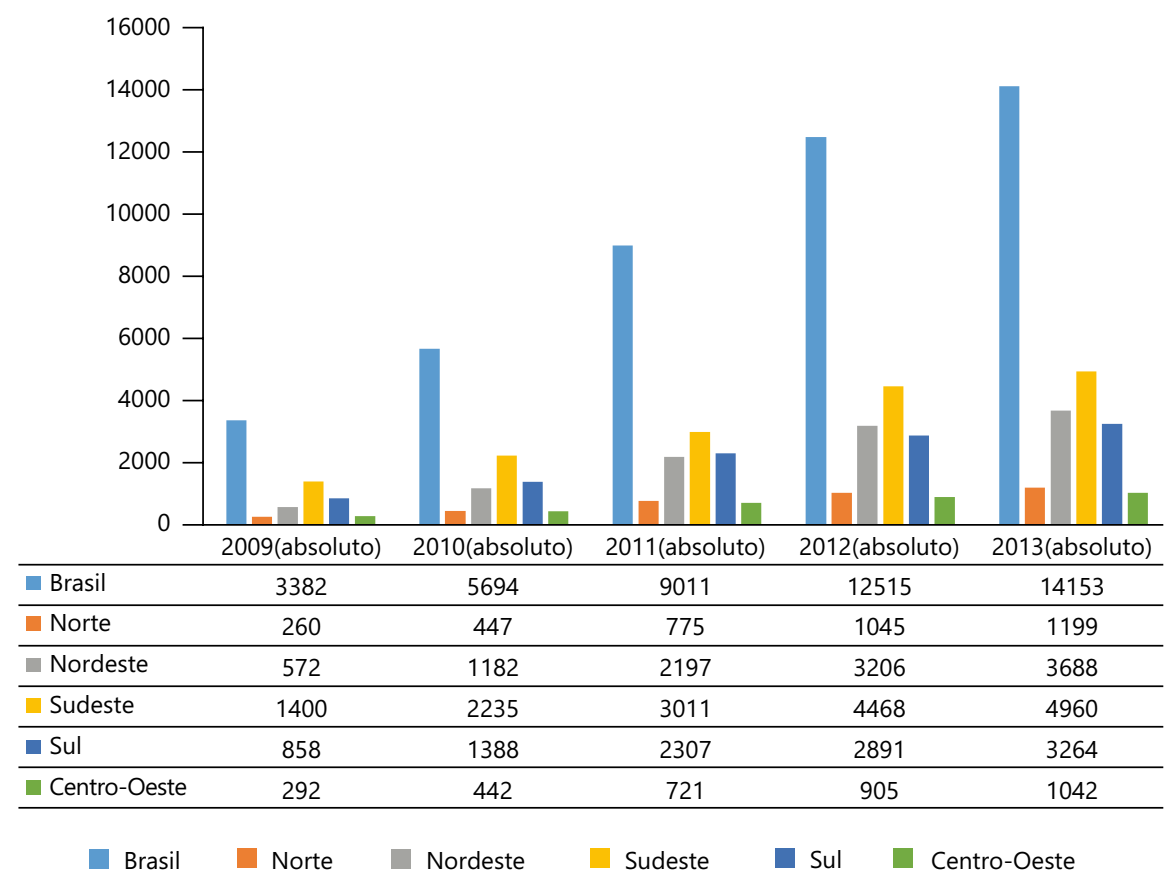

Fonte: INEP (2013) - gráfico elaborado pelas autoras em abril de 2016.

Figura 2. Quantidade de escolas municipais com salas de recursos multifuncionais em uso.

Nesse sentido, é importante ressaltar que o ingresso desses alunos nas salas regulares não assegura a implementação da Meta 4 do PNE, que preconiza, em suas diretrizes estratégicas, no item 4.8 , que se refere a "articulação pedagógica", a garantia da oferta de educação inclusiva por meio da promoção da articulação entre o ensino regular e o atendimento educacional especializado.

Portanto, para que se possa analisar melhor a articulação pedagógica a seguir, apresentamse os gráficos (Figura 2, Figura 3 e Figura 4), referentes à implantação e ao uso das salas de recursos multifuncionais nas redes de ensino municipais e estaduais do Brasil.

Conforme exposto, por meio dos dados apresentados, é possível observar que de um total de 16.644 escolas municipais que possuem salas multifuncionais, 2.501 delas não utilizam essas salas.

Esses números representam as fragilidades no acompanhamento da distribuição e na implementação desses recursos, bem como em sua utilização em benefício 


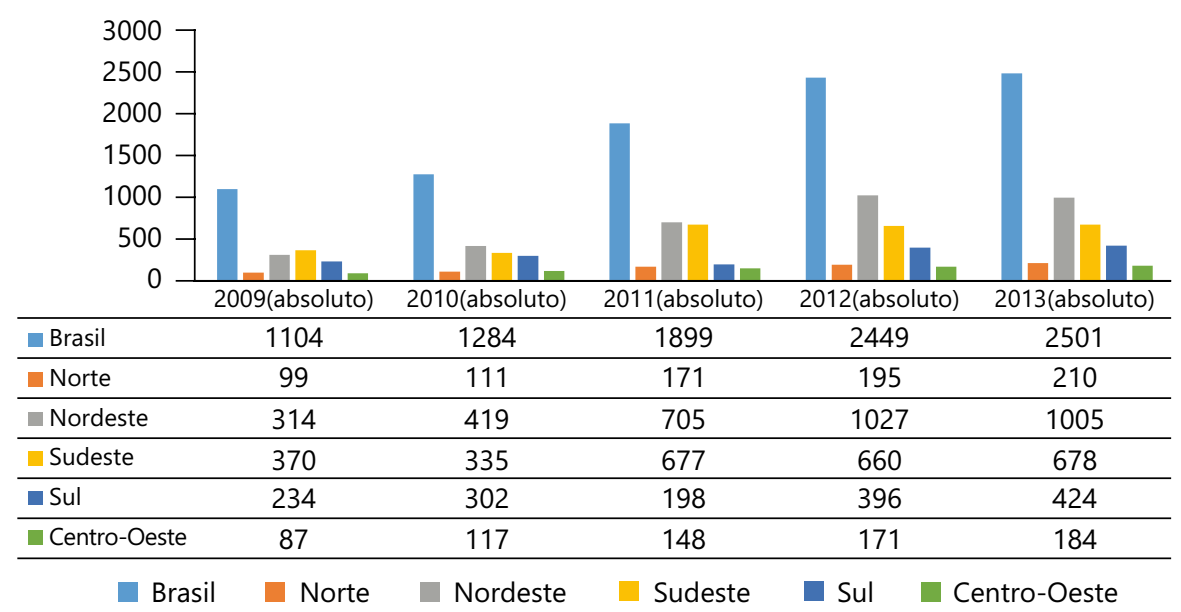

Fonte: INEP (2013) - gráfico elaborado pelas autoras em abril de 2016.

Figura 3. Quantidade de escolas municipais com salas de recursos multifuncionais sem uso.

da aprendizagem dos alunos da educação especial, sejam eles deficientes, com altas habilidades ou superdotados.

Nesse sentido, vale ressaltar que os gestores educacionais, na implementação de ações pedagógicas voltadas para esse público, devem dispor de todos os recursos disponíveis para atender à diversidade de estratégias necessária para atender a esses alunos, portanto é preciso que se atentem para a utilização efetiva dos recursos disponíveis nas salas de recursos multifuncionais

Além disso, é preciso voltar a atenção para os dizeres da estratégia 4.10:

Fomentar pesquisas voltadas para o desenvolvimento de metodologias, materiais didáticos, equipamentos e recursos de tecnologia assistiva, com vistas à promoção do ensino e da aprendizagem, bem como das condições de acessibilidade dos estudantes com deficiência, transtornos globais do desenvolvimento e altas habilidades ou superdotação (BRASIL, 2014).

Outro aspecto importante a ser levado em conta é a evolução da quantidade de docentes no atendimento educacional especializado, em comparação com o número de matrículas. Observa-se uma evolução nesse sentido, conforme o gráfico a seguir (Figura 5): 


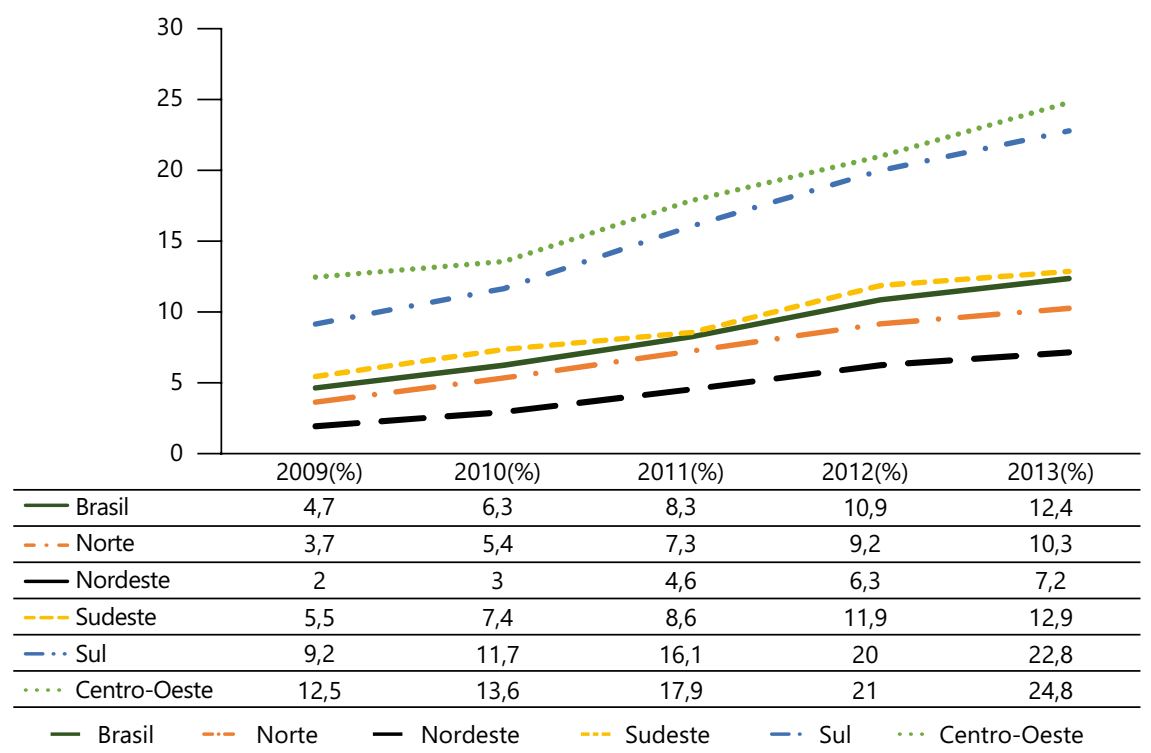

Fonte: INEP (2013) - gráfico elaborado pelas autoras em abril de 2016.

Figura 4. Evolução da porcentagem de todas as escolas do Brasil com salas de recursos multifuncionais em uso.

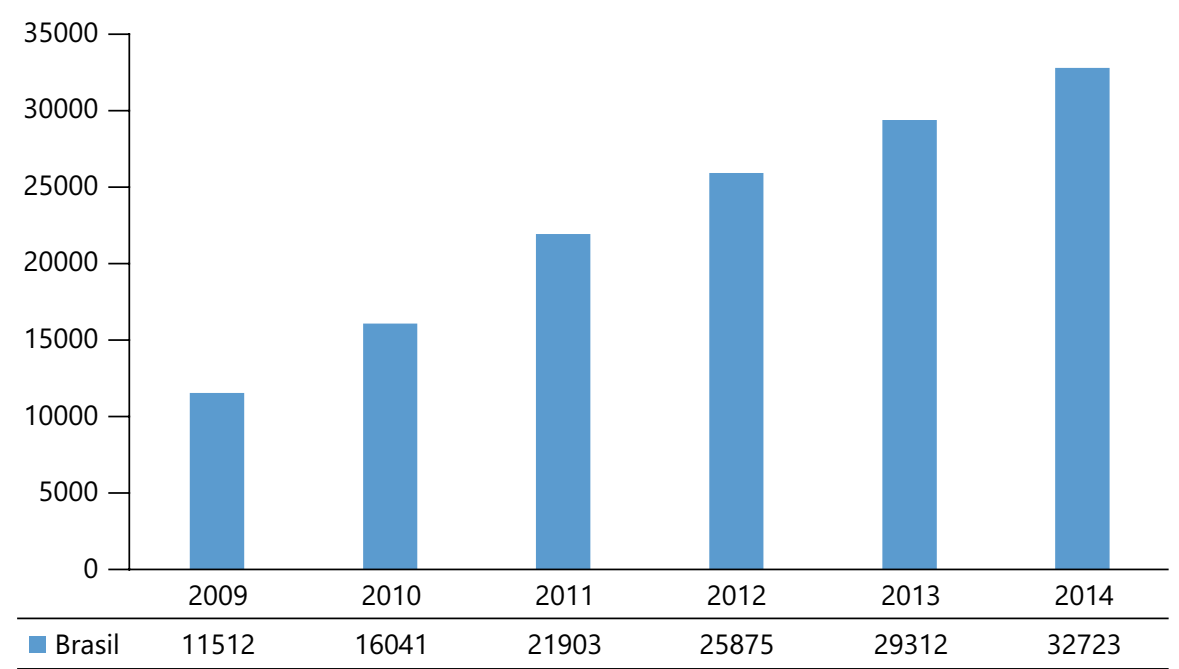

Fonte: INEP (2014) - gráfico elaborado pelas autoras em abril de 2016.

Figura 5. Número de funções docentes no Atendimento Educacional Especializado na rede pública. 
Temos uma evolução que mostra a alteração no número de 11.512 professores, em 2009, para 32.723 em 2014.

Esses números poderiam apresentar um crescimento significativo se fossem olhados de forma isolada, sem se atentar para a evolução das matrículas de alunos da educação especial, que, em 2014, foi de 698.768 matriculados em classes comuns. Sendo assim, pode-se constatar que existiam aproximadamente 21.000 alunos para cada professor na função do atendimento educacional especializado.

Além dessa defasagem, os números referentes à evolução das escolas com dependências adequadas para o atendimento aos alunos com deficiência ou mobilidade reduzida, também mostram que há muito a se fazer para evolução desse indicador (Figura 6). De acordo com as estatísticas, em 2012, o Brasil ainda possuía mais de $50 \%$ de suas escolas sem a infraestrutura necessária para atender aos alunos com deficiência ou mobilidade reduzida. Não foram encontrados dados mais recentes para esse indicador.

$\mathrm{O}$ recorte de indicadores utilizados neste estudo apresenta alguns pontos de atenção, no que se refere ao alcance da Meta 4 do PNE, pois, conforme exposto,

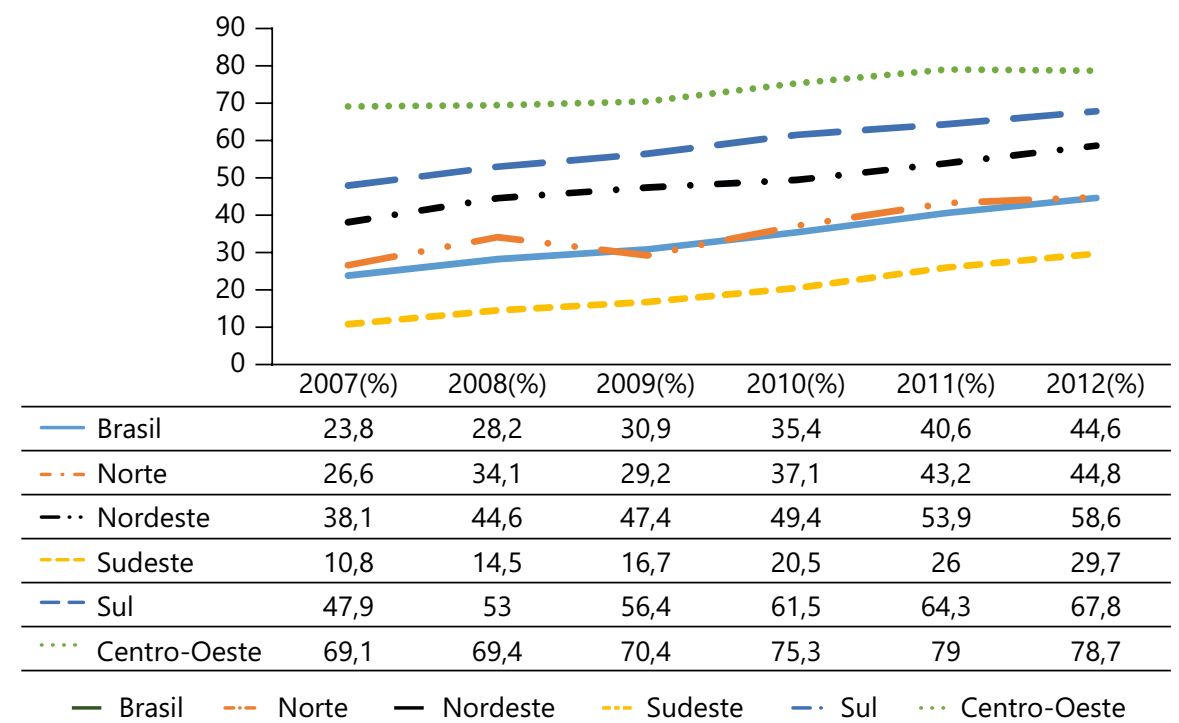

Fonte: INEP (2012) - gráfico elaborado pelas autoras em abril de 2016.

Figura 6. Evolução da porcentagem de escolas com dependências e vias adequadas a alunos com deficiência ou mobilidade reduzida. 
existe a necessidade de um olhar mais criterioso para a coleta de dados do Censo Escolar e do Censo Demográfico, relativos às questões da educação inclusiva, considerando que os dados levantados atualmente não contemplam de forma fidedigna todos indicadores necessários para o acompanhamento do desenvolvimento da referida meta.

\section{Considerações finais}

Proporcionar ao aluno com deficiência um desenvolvimento com equidade de oportunidades é mais do que formalizar a igualdade de direitos em leis e decretos ou disponibilizar recursos alternativos para a aprendizagem. Um ambiente escolar realmente atento ao desenvolvimento de uma Cultura Inclusiva proporciona a esse aluno condições para interagir ativamente no contexto social, levando em conta as adaptações necessárias, mas, acima de tudo, capacitando o professor para a promoção de uma convivência coletiva, onde todos os alunos se sintam pertencentes ao grupo - pois esses sentimentos de pertencimento e de identificação com o grupo são extremamente necessários para um desenvolvimento mais eficaz do indivíduo.

Na questão metodológica, o estudo apresentou a necessidade da existência de base de dados mais precisos para a produção de indicadores que produzam respostas que reflitam, de fato, a realidade e sejam, assim, propulsores para o atingimento da Meta 4. Para isso, sugere-se que as pesquisas populacionais, nesse caso o Censo Demográfico do IBGE e o Censo Escolar, cheguem a um conceito comum de deficiência para que as pesquisas possam ser comparativas, de preferência, utilizando as definições estabelecidas pelos professores estudiosos da área, como afirmam Rodrigues, Capellini e Santos (2014):

As definições descritas pela academia são importantes porque expressam segmentos da sociedade e auxiliam na elaboração de leis que pretendem garantir o acesso às pessoas com deficiência, bem como as possibilidades de relações sociais, a todos os contextos. Todavia, nem sempre comungamos de todas as nuances presentes nas leis brasileiras (p. 11).

É válido colocar, também, que os resultados de pesquisas, em relação à Educação, ficariam mais precisos se o Censo Demográfico do IBGE colhesse informações mais detalhadas, em relação à idade e à escolarização das pessoas que se declararam com deficiência, não sendo suficiente a classificação em faixa etária, pois ela nos dá uma noção mais ampliada, o que não permite traçar um perfil mais bem definido desse público em questão. 
Vale ressaltar que o Plano Nacional de Educação apresenta 19 estratégias para o atingimento da Meta 4, e que cada uma delas merece a atenção de pesquisadores e especialistas no sentido de fomentar as discussões e apontar os melhores caminhos para que as políticas públicas e ações no interior de cada unidade escolar possam alcançar todos os alunos, sem distinção, sempre visando, de fato, à inclusão efetiva e ao acesso de todos à educação.

Por fim, é importante reconhecer a jovialidade da concretização em leis de objetivos relevantes para a Educação, o que marca historicamente esse momento como um cenário aberto a contribuições e estabelecimento de novas concepções acerca da Educação e da Inclusão. 


\title{
The National Education Plan 2014-2024 and the challenges for Special Education in the perspective of an Inclusive Culture
}

\begin{abstract}
This study deals with Brazil's efforts to implement educational public policies aimed at creating an Inclusive Culture. A brief historical review related to the struggles that have been made until today (when public policies connected to this subject finally exist) to guarantee rights is presented. The analysis is done with the collection of indicators for goal 4 of the National Education Plan that deals with the formation of actions focused on Inclusive Education for the next decade. In this sense, data are presented on the evolution of enrollment of students with disabilities; on the training of teachers that are able to attend this specific audience; and on the implementation and usage of multifunctional resource rooms. The references come from the database of INEP (National Institute of Studies and Educational Research Anísio Teixeira). Analyzed data consider the crossing between the numbers of the School Census and the Demographic Census of IBGE (Brazilian Institute of Geography and Statistics).
\end{abstract}

Keywords: National Education Plan 2014-2024. Inclusive Education. Inclusive Culture.

\section{El Plan Nacional de Educación 2014-2024 y los desafíos para la Educación Especial en la perspectiva de una Cultura Inclusiva}

\section{Resumen}

Este estudio se sitúa ante los caminos que vienen siendo trillados en Brasil en la implementación de políticas públicas en el área de la educación, orientadas hacia una Cultura Inclusiva. Se presenta un breve relevamiento histórico sobre el trayecto de las luchas sociales, en la garantía de derechos, hasta el momento en que políticas públicas están atentas a ese tema. El recorte analítico se da en el levantamiento de indicadores para la meta 4 del Plan Nacional de Educación, la cual establece la planificación de acciones dirigidas a la Educación Inclusiva para la próxima década. En este sentido, se presentan datos sobre: la evolución de las matrículas de alumnos con discapacidad, formación de docentes para atender a esos públicos especificos y relativos a la implantación y al uso de las salas de recursos multifuncionales. Las referencias utilizadas proceden de la base de datos del INEP (Instituto Nacional de Estudios e Investigaciones Educativas Anísio Teixeira). Los datos analizados consideran el cruce de los números del Censo Escolar y del Censo Demográfico del IBGE (Instituto Brasileño de Geografía y Estadística).

Palabras clave: Plan Nacional de Educación 2014-2024. Educación Inclusiva. Cultura Inclusiva. 


\section{Referências}

ALVARENGA, C. H. A.; MAZZOTTI, B. T. Análise dos argumentos que apresentam as 20 metas do Plano Nacional de Educação. Ensaio: Avaliação e Políticas Públicas em Educação, v. 25, n. 94, p. 182-206, jan./mar. 2017. https://dx.doi.org/10.1590/s0104-40362017000100007

BARROS, B.; SILVA, A.M.; COSTA, M. P. R. Dificuldades no processo de inclusão escolar: percepções de professores e de alunos com deficiência visual em escolas públicas. Boletim Academia Paulista de Psicologia, v. 35, n. 88, p. $145-163,2015$.

BEZERRA, G. F. Enquanto não brotam as flores vivas: crítica à pedagogia da inclusão. 2012. 270 f. Dissertação (Mestrado em Educação)-Universidade Estadual de Mato Grosso do Sul, Paranaíba, 2012.

BEZERRA, F. G. A inclusão escolar de alunos com deficiência: uma leitura baseada em Pierre Bourdieu. Revista Brasileira de Educação, v. 22, n. 69, abr./jun. 2017. https://dx.doi.org/10.1590/s1413-24782017226924

BOOTH, T.; AINSCOW, M. Index for Inclusion: developing learning and participation in schools. Tradução de Mônica Pereira dos Santos e João Batista Esteves. 3rd ed. rev. ampl. Bristol: CSIE, 2012.

BRASIL. Constituição (1988). Constituição da República Federativa do Brasil. Brasília, DF, 1988.

. Lei $\mathrm{N}^{\circ}$ 9.394, 20 de dezembro de 1996. Estabelece as diretrizes e bases da educação nacional. Diário Oficial da União, 23 dez. 1996.

. Lei $\mathrm{N}^{\mathrm{o}} 10.172$, de 9 de janeiro de 2001. Aprova o Plano Nacional de Educação e dá outras providências.. Diário Oficial da União, 10 jan. 2001.

. Lei $\mathrm{n}^{\circ}$ 13.146, de 6 de julho de 2015. Institui a Lei Brasileira de INCLUSÃO DA PESSOA COM DEFICIÊNCIA: Estatuto da Pessoa com Deficiência. Diário Oficial da União, 7 jul. 2015.

. Ministério da Educação. Secretaria de Educação Especial. Secretaria de Educação Fundamental. Parâmetros Curriculares Nacionais: adaptações curriculares. Brasília, DF, 1998. 
BRASIL. Ministério da Educação. Secretaria de Educação Especial. Política Nacional de Educação Especial na perspectiva da Educação Inclusiva. Brasília, DF, 2008b. Disponível em: http://portaldoprofessor.mec.gov.br/ storage/materiais/000001. Acesso em: 15 jan. 2016.

. Ministério da Educação e Cultura. Secretaria de Educação Especial. Decreto $n^{\circ}$. 6.571, de 17 de setembro de 2008a. Dispõe sobre o atendimento educacional especializado, regulamenta o parágrafo único do Art. 60 da Lei $\mathrm{n}^{\circ}$. 9.394, de 20 de dezembro de 1996, e acrescenta dispositivo ao Decreto $\mathrm{n}^{\circ}$. 6.253, de 13 de novembro de 2007. Diário Oficial [da] República Federativa do Brasil, 17 set. 2008.

. Ministério da Educação Cultura. Planejando a próxima década: conhecendo o PNE. Brasília, DF, 2014. Disponível em: http://pne.mec.gov.br/ conhecendo-o-pne. Acesso em: 12 jan. 2016.

INSTITUTO NACIONAL DE ESTUDOS E PESQUISAS EDUCACIONAIS ANÍSIO TEIXEIRA - INEP. Censo Escolar, 2012. Brasília, DF, 2013. Disponível em: http://portal.inep.gov.br/censoescolar. Acesso em 12 jun. 2016.

. Censo Escolar, 2013. Brasília, DF, 2014. Disponível em : http://portal.inep.gov.br/censo-escolar. Acesso em 12 jun. 2016.

. Censo Escolar, 2014. Brasília, DF, 2015. Disponível em: http://portal.inep.gov.br/censo-escolar. Acesso em 12 jun. 2016.

LOPES, A. S. Considerações sobre a terminologia alunos com necessidades educacionais especiais. Revista Educação Especial, v. 27, n. 50, p. 737-750, set./dez. 2014. https://dx.doi.org/10.5902/1984686X13355

MARTINS, S. O.; LEITE, L. P. As contribuições da Educação Especial para promoção da educação inclusiva nas normativas brasileiras. Psicología, Conocimiento y Sociedad, v. 4, n. 2, 2014. Disponível em: <http://www. redalyc.org/comocitar.oa?id=475847269009>. Acesso em: 17 fev. 2018.

MATOS, S. N.; MENDES, E. G. A proposta de inclusão escolar no contexto nacional de implementação das políticas educacionais. Práxis Educacional, v. 10, n. 16, p. 35-39, jan./jun. 2014.

OBSERVATÓRIO do PNE. Metas do PNE: educação especial/inclusiva. 2013. Disponível em: $<$ http://www.observatoriodopne.org.br/metas-pne/4-educacaoespecial-inclusiva $>$. Acesso em: 20 jul. 2016. 
RODRIGUES, O. M. P. R.; CAPELLINI, V. L. M. F.; SANTOS, D. A. N. Fundamentos históricos e conceituais da educação especial e inclusiva: reflexões para o cotidiano escolar no contexto da diversidade. 2014. Disponível em: $<$ https://acervodigital.unesp.br/bitstream/unesp/155246/1/ unesp-nead_reei1_ee_d01_s03_texto02.pdf $>$. Acesso em:10 ago. 2016.

\section{Informações das autoras}

Janaina de Oliveira Macena: Mestra em Psicologia do Desenvolvimento e Aprendizagem pelo Programa de Pós-graduação em Psicologia do Desenvolvimento e da Aprendizagem da Faculdade de Ciências - Unesp-Bauru, São Paulo, Brasil. Contato: om.janaina@gmail.com

Laura Regina Paniagua Justino: Mestra em Psicologia do Desenvolvimento e Aprendizagem pelo Programa de Pós-graduação em Psicologia do Desenvolvimento e da Aprendizagem da Faculdade de Ciências - Unesp-Bauru, São Paulo, Brasil. Contato: lauraregina.p@gmail.com

Vera Lúcia Messias Fialho Capellini: Profa. Doutora com Pós-Doutorado em Educação Especial. Profa. Adjunta do Departamento de Educação, Programa de Pós-graduação e Psicologia do Desenvolvimento e da Aprendizagem e em Docência da Educação Básica da Faculdade de Ciências - Unesp-Bauru, São Paulo, Brasil. Contato: verinha@fc.unesp.br 